Jari Juga, Jouni Juntunen and Timo Koivumäki

University of Oulu, Oulu Business School, Finland

\title{
Willingness to share personal health information: impact of attitudes, trust and control
}

Records M anagement Journal (Author accepted manuscript)

\begin{abstract}
Purpose: The study explicates the behavioral factors that determine willingness to share personal health data for secondary uses.

Design/methodology/approach: A theoretical model is developed and tested with structural equation modeling using survey data from Finland.
\end{abstract}

Findings: It is shown that attitude towards information sharing is the strongest factor contributing to the willingness to share personal health information. Trust and control serve as mediating factors between the attitude and willingness to share personal health information.

Research limitations/implications: The measures of the model need further refinement to cover the various aspects of the behavioral concepts.

Practical implications: The model provides useful insights into the factors that affect the willingness for information sharing in healthcare and in other areas where personal information is distributed.

Social implications: Sharing of personal health information for secondary purposes can offer social benefits through improvements in healthcare performance.

Originality/value: A broad-scale empirical data gives unique view of attitudes towards sharing of personal health information in one national setting.

\section{Key words}

personal health information; attitude; control; trust; structural equation modeling 


\section{Introduction}

Digitization of healthcare processes, personal health records and medical information (Noffsinger and Chin, 2000; Agarwal et al., 2010; Hawathorne and Richards, 2017; Koumaditis and Hussein, 2018) together with technological advances such as cloud computing (Kuo, 2011; Sultan, 2014) and data analytics (Khalifa and Zabani, 2016; M ehta and Pandit, 2018) are fundamentally changing clinical work, healthcare management, and medical R\&D activities. Among the advantages of digitality and connectivity are, for example, improved quality and reduced cost of healthcare as well as safer, more affordable and more accessible services for patients (Agarwal et al., 2010; Nguyen et al., 2016). With the advent of artificial intelligence and machine learning applications (Kononenko, 2001; Ramesh et al., 2004) also the opportunities for solving complex diagnostic and prognostic medical problems are accelerated and the efficiency and effectiveness of healthcare improved.

As healthcare gets digitized, the improvements enabled by technological advances become inevitably traded off against the potentially negative consequences (Anderson and Agarwal, 2011). One of the biggest challenges arises from the highly sensitive nature of health information and the various risks related to its disclosure (Beckerman et al., 2008). Thus, in the healthcare sector there is a need for constantly balancing the requirements for personal privacy against the benefits that may accrue to society as a whole from the more widespread use of personal health information (Whiddett et al., 2006).

M any organizations in healthcare and public administration have paid attention to privacy and confidentiality questions by issuing guidelines and standards for patient information management. In the UK, for instance, the House of Commons recently published a briefing paper (Parkin, 2018) outlining safeguarding arrangements for confidential patient information based on the new requirements of the EU General Data Protection Regulation (GDPR). Another example focusing especially on the secondary use of health data is the White Paper by the American M edical Informatics Association (Safran et al., 2007). Secondary use of health data refers to the non-direct care use of personal health information, including but not limited to analysis, research, quality and safety measurement, public health, payment, provider certification or accreditation, and marketing and other business activities.

Although digitization is advancing rapidly, relatively little is known about the people's attitudes towards the use and sharing of personal health information. In a study among primary care patients in New Zealand (Whiddett et al., 2006) it was found that the willingness to share information was influenced by three factors: the nature of the recipient (health professionals, health administrators and researchers more acceptable); nature of information (lower willingness to share sensitive and private information); and identification (anonymity preferred). Another study in the US (Weitzman et al., 2010) indicated that the willingness to share information was conditioned by anonymity, research use, engagement with a trusted 
intermediary, and transparency around the access and use of the data. In addition, the patient's health status also affects the attitudes towards personal health data use (Lafky and Horan, 2011).

According to Anderson and Agarwal (2011), the willingness to disclose personal health information is based on an individual's "privacy calculus" where trust and risks are weighed against each other to maximize positive outcomes and minimize negative ones. Contextual factors related to requesting stakeholder and the purpose for which the information is requested play an important role in moderating the relationship of the privacy calculus. In a qualitative study among patients and healthcare personnel, Stone et al. (2005) found little evidence of privacy concerns regarding data sharing for public research purposes; however, it seemed that the patients generally lacked knowledge about the type of data held in general practice records and the ways in which they are shared.

In a recent review study by Kalkman et al. (2019) it was found that the benefits of data sharing are generally recognized among patients and the public, but there are also concerns about the breaches of confidentiality and potential abuses of the data. Another review study, by Lea et al. (2018), pointed out the need for privacy protection efforts to mitigate the technical, legal, social and ethical challenges related to the re-use of health data for clinical research. Delving deeper into the question of trust in relation to science and scientific research practices, Aitken et al. (2016) observed that the levels of support for data sharing and research access to personal medical information depended on a range of factors such as institutional arrangements for data sharing processes, transparency of process and the existence of robust accountability procedures. Moreover, the extent to which individuals anticipated that members of the public could have control over their personal medical data, or could play a role in overseeing data sharing processes also influenced perceptions of trustworthiness.

To further explore the factors behind people's preparedness to health information sharing, this study aims to explicate the factors that determine willingness to share personal health information. The focus is on behavioral determinants, so for instance demographic factors will not be examined. The study deals with secondary use of health information for various types of medical research and health-related development activities. Personal health information (PHI) in this study is used as a generic concept, without any specific reference to particular categories such as electronic health records (EHR), electronic medical records (EM R), personal health records (PHR), etc.

A theoretical model is developed indicating the hypothesized antecedents of willingness to share PHI. Empirical data of a broad-scale survey study in Finland is then used for testing the theoretical model. The dimensionality of the survey variables is analyzed using exploratory factor analysis and the proposed model is then tested with structural equation modeling (SEM). Even if the population in Finland is quite limited in size, the country is among the forerunners in the development and use of e-health and ICT in healthcare 
(Tavares, 2018), thus offering a suitable context for studying public attitudes towards sharing and utilization of personal information in healthcare.

\section{Research model and hypotheses}

Although there is some controversy related to the relationship between attitudes and behavior (Ajzen and Fishbein, 2005), it is widely accepted in consumer research that attitudes influence a person's behavioral intentions and consequently behavior (Nicosia, 1996). Attitudes are based on beliefs and feelings that form a person's predisposition to respond in a consistently favorable or unfavorable manner with respect to a given object (Engel et al., 1995). In the popular technology acceptance model (TAM), for instance, the person's beliefs regarding the usefulness and ease of use determine his or her attitude towards accepting a new technological tool or application (Davis, 1989).

Attitudes towards the disclosure of personal information in the Internet and social media applications are based on an individual assessment of risks and benefits of information sharing: willingness to disclose increases when the perceived benefits justify the costs such as time consumption and privacy concerns (Olivero and Lunt, 2004). Similarly, the willingness to share personal health information is based on balancing privacy and safety concerns with the possibility for personal or societal gain from information sharing between the various stakeholders (Whiddett et al., 2006; Perera et al., 2011). It seems that people rely on public health agencies and the willingness to share personal health data for altruistic purposes such as medical research is high (Stone et al., 2005; Weitzman et al., 2010). Thus, it is hypothesized in this study that:

$\mathrm{H1}$ : Attitudes towards sharing personal health data influence the willingness to share personal health data for medical and research purposes.

Positive attitude is not the only explanation for information sharing willingness - instead, the privacy concerns and other risk factors can be mitigated with the development of trust and the capability to control the information one is expected to share (Olivero and Lunt, 2004). Trust in online environment is concerned with the expectation that one's vulnerabilities in a risk situation will not be exploited (Corritore et al., 2003). In marketing, trust has been found as an effective way for managing the consumer's privacy concerns (Nam et al., 2006; Campbell, 1997) and it has also been identified as a strong predictor of the intention for disclosing personal health information online (Bansal et al., 2010). In this study, trust is seen in a mediating role between attitudes and intention to share $\mathrm{PHI}$, and so it is hypothesized that:

H2: Perceived trust serves as a mediator between the attitudes and willingness to share personal health data for medical and research purposes. 
Besides lacking trust, the consumer's unwillingness to disclose can be based on the perceived lack of control over the use of personal information against one's interest (Olivero and Lunt, 2004). It has been shown that the support for medical data sharing diminishes if suggested uses include commercial, profit and marketing applications - in such cases, patients prioritize personal control and strict restrictions on data use as prerequisites for sharing medical data (Weitzman et al., 2010). Besides the acceptability of recipient, also factors such as the sensitivity and identifiability of information affect the willingness for sharing medical data (Whiddett et al., 2006) Due to differing patient preferences, it has been suggested that control should be differentiated according to data sensitivity, use, recipient etc. (Caine and Hanania, 2013). As a general principle, however, the patient should always maintain control over the use of his/her personal information (Anderson and Agarwal, 2011; M osquera, 2009). Following these arguments it is hypothesized that:

H3: Perceived control serves as a mediator between attitudes and willingness to share personal health data for medical and research purposes.

A graphical illustration of the proposed research model is presented in Figure 1. The hypothesized main effect $(\mathrm{H} 1)$ is shown as the direct relationship between the attitude and intended behavior regarding personal health information sharing. The hypothesized mediating effects of perceived trust $(\mathrm{H} 2 \mathrm{a}, \mathrm{H} 2 \mathrm{~b})$ and perceived control $(\mathrm{H3a}, \mathrm{H3b})$ supplement the main effect in the proposed model. The intended behavior is represented by two dimensions of willingness to share personal health information $(\mathrm{H} 4 \mathrm{a}, \mathrm{H} 4 \mathrm{~b})$ - one describing personal health information generally and the other focusing on health information in combination with demographic, lifestyle and other additional personal data.

Figure 1 here

A mediation effect involves the mechanism that underlies an observed relationship between the independent variable and the dependent variable via the inclusion of an intervening variable, the mediator. Thus, the mediator variable serves to clarify the nature of the relationship between the independent and the dependent variables (M acKinnon, 2008). In this study, the two mediators are included to complement the main effect because it is assumed that the privacy concerns related to the willingness to share personal information will not be fully captured by the attitudinal determinant in the model. The dependent variable is divided into two dimensions because the sensitivity of information has been shown to affect the willingness to share personal information. By combining lifestyle and demographic data with personal 
health information (even if the data is unidentifiable), an element of sensitivity is added and the distinction can thus offer analytical richness to the study.

\section{Data and method}

The empirical data was collected in Finland in June 2016 by Kantar TNS Oy, a leading market research company in Finland, on commission from the Finnish Innovation Fund, Sitra for a national project titled "Secondary Use of Health and Social Care Data 2016". The data is available for research purposes at the Finnish Social Science Data Archive, http://www.fsd.uta.fi/en/data/catalogue/FSD3132/. In total, the data set includes 2338 usable responses from Finnish population aged 15-79 years. The data was collected as a stratified sample from the national respondent panel administered by Kantar TNS Oy. The sample was weighted to correspond with the target population in terms of gender, age and place of residence. The language of the original survey was Finnish, English translations have been used for this study.

The questionnaire was designed to cover a variety of information needs by the research commissioner (Sitra) - all in all 153 variables were included in the original survey questionnaire. A subset of questions relevant for this study was chosen for measuring the concepts in the proposed research model (28 variables, see Appendix 1). In this paper, we have kept the original variable labels for replicability and continuing analysis purposes. Before the statistical analyses the "no opinion" answers were recoded into missing values.

The representativeness of the sample was analyzed with two demographic variables, age and gender. As can be seen in Table 1, there is a slight under-representation among the younger and male respondents in the sample if compared with the entire Finnish population. Nevertheless, the overall composition of the sample is considered entirely satisfactory and the representativeness of the data is therefore deemed acceptable for this study.

Table 1 here

The empirical analysis methods include exploratory factor analysis (EFA) for examining the constructs that underlie the measurement variables in the survey data, and structural equation modeling (SEM) for testing the hypothesized relationships between the latent constructs as proposed in the theoretical model. In SEM terminology, the dependent construct of the model can be described as a second-order factor as the construct (willingness to share information) is formed of two distinct but related lower-order constructs (two types of personal health information). The IBM SPSS statistical software package was used for 
computing descriptive statistics and exploratory factor analysis while structural equation modeling was performed with the MPlus software package.

\section{Analyses and results}

To gain an overview of the dimensionality of data, a preliminary analysis was conducted with exploratory factor analysis using the principal axis factoring method. In this analysis, five factors were identified that conform with the constructs of the proposed theoretical model. The rotated factor solution (Table 2 ) shows high factor loadings for all the variables used in the study. Hence, this five-factor solution (Q24 attitude; Q12 trust; Q14 control; Q17 willingness to share A; Q21 willingness to share B) was adopted as the foundation for model testing with the structural equation modeling procedure.

Table 2 here

The theoretical model was next tested with structural equation modeling using the maximum likelihood method. The proposed model showed a good fit to the data. All relationships in the model were found to be statistically significant and the test values show adequate reliabilities for the concepts. The empirical model is shown in Figure 2 and a summary of the test values is presented in Table 3.

Figure 2 here

Table 3 here

The main effect between the attitude and the willingness to share personal health information $(\mathrm{H} 1)$ is the strongest of the hypothesized relationships in the model. As expected, trust plays in important role as a mediating variable $(\mathrm{H} 2 \mathrm{a}, \mathrm{H} 2 \mathrm{~b})$ facilitating the willingness to share personal health information. The mediating impact of control appears to be more complicated. While the attitude towards information sharing affects the demand for control positively ( $\mathrm{H3} 3$ ), the impact of control on information sharing willingness $(\mathrm{H} 3 \mathrm{~b})$ is negative. By increasing the control opportunities, the willingness towards the sharing of personal health information may actually decrease. The distinction between two dimensions of willingness to share information $(\mathrm{H} 4 \mathrm{a}, \mathrm{H} 4 \mathrm{~b})$ appears to be valid: the willingness to share is lower if demographic and lifestyle information is combined with health information, which can probably be explained by the increasing feeling of sensitivity even if the data were unidentifiable. 


\section{Discussion}

The purpose of this study was to explicate the factors that determine willingness to share personal health data for various secondary uses such as medical research and health care development activities. Based on a review of earlier literature, a theoretical model was developed outlining the behavioral antecedents that explain willingness to share personal health information (PHI) for secondary uses. These antecedents include: 1) the attitude towards sharing of $\mathrm{PHI}$; 2 ) trust in appropriate use of $\mathrm{PHI}$ by the concerned health care institutions; and 3) the ability to control the use of PHI for secondary purposes.

The main effect between the attitude towards sharing PHI and willingness to share PHI (H1) was found to be the strongest relationship in the empirical model. This finding is in line with previous studies related to health information sharing and reuse among patients and healthcare professionals (e.g. Whiddett et al., 2006; Perera et al., 2011; Joo et al., 2017). However, as has been shown in earlier research, also this study indicates that there are contingency factors affecting the main effect between the attitude and willingness towards healthcare information sharing.

Previous studies recognize the critical role of trust in mitigating privacy concerns when sharing sensitive information such as PHI (Stone et al., 2005; Bansal et al., 2010). In this study, too, the positive path coefficients for $\mathrm{H} 2 \mathrm{a}$ and $\mathrm{H} 2 \mathrm{~b}$ indicate that trust has a complementary impact alongside attitude as an antecedent to personal information sharing willingness in the health care context.

The mediating effect of control turned out to be an intriguing one. A positive relationship is observed between the attitude towards information sharing and perceived control ( $\mathrm{H} 3 \mathrm{a}$ ), while the relationship between control and the willingness to share information is negative ( $\mathrm{H} 3 \mathrm{~b})$. This is unexpected but not unexplainable: control is closely associated with privacy protection (Smith et al., 2011) and the willingness to share $\mathrm{PHI}$ is subjected to privacy concerns that explain the negative path coefficient for $\mathrm{H} 3 \mathrm{~b}$. It can be noted that also in other contexts, such as e-commerce, there is evidence showing contrasting effects of trust and control on information sharing willingness among online consumers (Olivero and Lunt, 2004).

Previous research has shown that the nature and recipient of information affects the willingness to share PHI. For instance, Whiddett et al. (2006) found that respondents were increasingly unwilling to share their information as it took on a more personal nature. In the present study, the willingness to share information was measured by two types of PHI: the willingness to share general $\mathrm{PHI}(\mathrm{H} 4 \mathrm{a})$ and the willingness to share $\mathrm{PHI}$ when combined with demographic and lifestyle data (H4b). Even if the information is unidentifiable, the respondents obviously find the latter type of $\mathrm{PHI}$ more sensitive and therefore the path coefficient of $\mathrm{H} 4 \mathrm{a}$ is higher than $\mathrm{H} 4 \mathrm{~b}$. 


\section{Conclusions}

The results of this study contribute to the research of PHI by explicating the behavioral constructs and their relationships that determine the willingness to share $\mathrm{PHI}$. It builds on previous research related to attitudes of sharing PHI (Whiddett et al., 2006; Perera et al., 2011) and utilizes structural equation modeling for hypothesis testing and model estimation. Using an extensive survey data collected in Finland, the proposed model showed to be statistically significant and therefore it offers a good starting point for continuing testing and development. Although the empirical material of this study is limited to one country, the model itself is generic and should be easily testable also in other contexts.

As can be expected from previous literature, attitude is the strongest behavioral determinant of the willingness to share personal health information for secondary uses. However, also trust and control play an important mediating role in mitigating the privacy concerns related to sharing of sensitive information such as personal health data. For the administrators of health information, giving attention to these mediating effects can be tricky: while trust-promoting efforts create a complementary impact to the attitude towards information sharing, the outcome of control-enhancing measures can be the opposite, i.e. reduced willingness of information sharing. At the same time, new legislation (e.g. EU's Data Protection Regulation) is increasing the opportunities for individuals to control their personal information in health care and other contexts.

All behavioral research struggles with the measurement of concepts such as attitudes. In this study, the attitudinal component was limited to the positive aspect (perceived benefits of information sharing) whereas the flip side (perceived risk) was excluded. In continuing research, both sides of the patient's "privacy calculus" could be included to fully capture the attitudinal dimension and measure the respective impacts on intended behavior. It should also be noted that the survey of this study was conducted before the Facebook data scandal and the introduction of the General Data Protection Regulation in 2018. In Finland, a severe data breach was revealed in 2020 related to patient health records of a private psychotherapeutic center, causing strong resentment and raising questions about general information security in healthcare. All the factors and incidents have probably increased the privacy concerns among the general public and a follow-up study to assess the presented results is therefore recommended.

In a dialogue paper recently published by the World Economic Forum (2014) three core objectives are laid down for strengthening trust on personal data use: transparency, accountability and empowerment. It could also be a direction for future research in the area of personal health information to establish measures guided by these general objectives and evaluate their impacts on information sharing attitudes. Experimental studies and use cases of health information sharing over different platforms could be elaborated to investigate the impact of attitudes and privacy concerns on information sharing willingness. 
Also qualitative research, in the line of Aitken et al. (2016) for instance, can offer insights for deepening the understanding of personal information sharing and its antecedents in different contexts. 


\section{References}

Agarwal, R., Gao G., DesRoches, C. and Jha, A.K. (2010), "The digital transformation of healthcare: Current status and the road ahead", Information Systems Research, Vol. 21, No. 4, pp. 769-809.

Aitken, M., Cunningham-Burley, S. and Pagliari, C. (2016), "M oving from trust to trustworthiness: Experiences of public engagement in the Scottish health informatics programme", Science and Public Policy, Vol. 43, No 5, pp. 713-723.

Ajzen, I. and Fishbein, M. (2005), "The Influence of attitudes on behavior", in: D. Albarracín, B.T. Johnson, and M .P. Zanna. (eds.) The handbook of attitudes, New York NY: Lawrence Erlbaum Associates, pp. 173221.

Anderson, C.L. and Agarwal, R. (2011), "The digitization of healthcare: boundary risks, emotion, and consumer willingness to disclose personal health information", Information Systems Research, Vol. 23, No. 3, pp. 469-490.

Bansal, G., Zahedi, F. and Gefen, D. (2010), "The impact of personal dispositions on information sensitivity, privacy concern and trust in disclosing health information online", Decision Support Systems, Vol. 49, No. 2 , pp. $138-150$.

Beckerman, J.Z., Pritts, J., Goplerud, E., Leifer, J.C., Borzi, P.A., Rosenbaum, S. and Anderson, D.R. (2008), “A delicate balance: Behavioral health, patient privacy, and the need to know", California Healthcare Foundation. https:// www.chcf.org/publication/a-delicate-balance-behavioral-health-patient-privacy-andthe-need-to-know/ [cited 20 Feb. 2020].

Caine, K. and Hanania, R. (2013), "Patients want granular privacy control over health information in electronic medical records", Journal of the American Medical Informatics Association, Vol. 20, No. 1, pp. 715.

Campbell, A.J. (1997), “Relationship marketing in consumer markets: A comparison of managerial and consumer attitudes about information privacy", J ournal of Interactive Marketing, Vol. 11, No. 3, pp. 44-57.

Corritore, C.L., Kracher, B. and Wiedenbeck, S. (2003), "Online trust: Concepts, evolving themes, a model”, International Journal of Human-Computer Studies, Vol. 58, No. 6, pp. 737-758.

Davis, F.D. (1989), "Perceived usefulness, perceived ease of use, and user acceptance of information technology", M IS Quarterly, Vol. 13, No. 3, pp. 319-340.

Engel, J.F., Blackwell, R.D. and Miniard, P.W. (1995) Consumer behavior, Dryden Press, Fort Worth. Hawthorne, K.H. and Richards, L. (2017), “Personal health records: A new type of electronic medical record", Records Management Journal, Vol. 27, No 3, pp. 286-301. 
Joo, S., Kim, S. and Kim, Y. (2017), "An exploratory study of health scientists' data reuse behaviors: Examining attitudinal, social, and resource factors", Aslib Journal of Information M anagement, Vol. 69, No 4, pp. 389-407.

Kalkman, S., van Delden, J., Banerjee, A., Benoït, T., M ostert, M . and van Thiel, D. (2019), "Patients' and public views and attitudes towards the sharing of health data for research: A narrative review of the empirical evidence", Journal of Medical Ethics, Published online 12 Nov. 2019, retrieved from: https://jme.bmi.com/content/early/2019/11/11/medethics-2019-105651.info.

Khalifa, M . and Zabani, I. (2016), "Utilizing health analytics in improving the performance of healthcare services: A case study on a tertiary care hospital", Journal of Infection and Public Health, Vol. 9, No. 6, pp. 757-765.

Kononenko, I. (2001), "Machine learning for medical diagnosis: history, state of the art and perspective", Artificial Intelligence in Medicine, Vol. 23, No. 1, pp. 89-109.

Koumaditis, K. and Hussain T. (2018), "Personal healthcare records research: past present and new dimensions", International Journal of Healthcare Technology and M anagement, Vol. 17, No 1, pp. 1-28. Kuo, M.H. (2011), "Opportunities and Challenges of Cloud Computing to Improve Health Care Services", Journal of M edical Internet Research, Vol. 13, No. 3, pp. e67

Lafky, D.B. and Horan, D.A. (2011), "Personal health records: Consumer attitudes toward privacy and security of their personal health information", Health Informatics J ournal, Vol. 17, No. 1, pp. 63-71.

M acKinnon, D.P. (2008) Introduction to Statistical Mediation Analysis. Lawrence Erlbaum Associates, New York.

Lea, N.C., Nicholls, J. and Fitzpatrick, N.K. (2018), “Between Scylla and Charybdis: Charting the wicked problem of reusing health data for clinical research informatics", IM IA Yearbook of M edical Informatics, Vol. 27, No 1, pp. 170-176.

M ehta, N. and Pandit, A. (2018), "Concurrence of big data analytics and healthcare: A systematic review", International Journal of Medical Informatics, Vol. 114, pp. 57-65.

M osquera, M . (2009) Privacy experts face off over patient control, policy safeguards. Healthcare IT News. https://www.healthcareitnews.com/news/privacy-experts-face-over-patient-control-policy-safeguards [cited 20 Feb.2020].

Nam, C., Song, C., Lee, E. and Park, C.I. (2006), “Consumers' privacy concerns and willingness to provide marketing-related information online, Advances in Consumer Research, Vol. 33, No. 1, pp. 212-217. 
Nguyen, H.T.T., Eikebrokk, T.R., M oe, C.E., Tapanainen, T. and Dao, T.K. (2016), “Exploring health information technology success factors: a comparative investigation in Nordic countries", International Journal of Healthcare Technology and Management, Vol. 15, No 4, pp. 326-351.

Nicosia, F.M . (1996) Consumer decision processes: marketing and advertising implications. Prentice-Hall, Englewood Cliffs NJ.

Noffsinger, R. and Chin, S. (2000), "Improving the delivery of care and reducing healthcare costs with the digitization of information", J ournal of Healthcare Information Management, Vol. 14, No 2, pp. 23-30.

Olivero, N. and Lunt, P. (2004), "Privacy versus willingness to disclose in e-commerce exchanges: The effect of risk awareness on the relative role of trust and control", Journal of Economic Psychology, Vol. 25, No. 2, pp. 243-262.

Parkin, E. (2018) Patient health records and confidentiality. House of Commons Library, No 07103, 25 M ay 2018. https://researchbriefings. parliament.uk/ResearchBriefing/Summary/SN07103 [cited 20 Feb. 2020].

Perera, G., Holbrook, A., Thabane, L., Foster, G. and Willison, D.J. (2011), "Views on health information sharing and privacy from primary care practices using electronic medical records", International Journal of Medical Informatics, Vol. 80, No. 2, pp. 94-101.

Ramesh, A.N., Kambhampati, C., M onson, J.R.T. and Drew, P.J. (2004), "Artificial intelligence in medicine", Annals of the Royal College of Surgeons of England, Vol. 86: 334-338.

Safran, C., Bloomrosen, M., Hammond, W.E., Labkoff, S., Markel-Fox, S., Tang, P.C. and Detmer, D.E. (2007), "Toward a national framework for the secondary use of health data: An American M edical Informatics Association White Paper", Journal of the American Medical Informatics Association, Vol. 14, No. 1, pp. 1-9. Smith, H.J., Dinev, T. and Xu, H. (2011), "Information privacy research: An interdisciplinary review", M IS Quarterly, Vol. 35, No. 4, pp. 989-1016.

Stone, M.A., Redsell, S.A., Ling, J.T. and Hay, A.D. (2005), "Sharing patient data: competing demands of privacy, trust and research in primary care", British Journal of General Practice, Vol. 55, pp. 783-789. Sultan, N. (2014), "M aking use of cloud computing for healthcare provision: Opportunities and challenges", International Journal of Information Management, Vol. 34, No. 2, pp. 177-184.

Tavares, A.I. (2018), "eHealth, ICT and its relationship with self-reported health outcomes in EU countries", International Journal of Medical Informatics, Vol. 112: 104-113.

Weitzman, E.R., Kaci, L. and M andl, K.D. (2010), “Sharing medical data for health research: The early personal health record experience", Journal of Medical Internet Research, Vol. 12, No. 2, pp. e14. 
Whiddett, R., Hunter, I., Engelbrecht, J. and Handy, J. (2006), “Patients' attitudes towards sharing their health information", International Journal of M edical Informatics, Vol. 75, No. 7, pp. 530-541.

World Economic Forum (2014) Rethinking personal data: A new lens for strengthening trust. Industry Agenda prepared in collaboration with A.T. Kearney.

http://www3.weforum.org/docs/WEF_RethinkingPersonalData_ANewLens_Report_2014.pdf [cited 20 Feb. 2020]. 
Appendix 1. Survey questionnaire (selected questions)

\begin{abstract}
Attitude
Question: Please indicate how important the following factors are for you:

Scale: 1 very important, 2 quite important, 3 not very important, 4 not at all important, (5 no opinion).

q24_1 My physician has access to as comprehensive information as possible about treatments and results that have been achieved earlier in Finland with patients like me.

q24_2 Treatment results are monitored on national level so that patients are in equal position and treatments are directed to patients who get the most benefit from them.

q24_3 Existing information is utilized effectively for development of services and health care.

q24_4 Information is provided about the possibilities for utilization of health information (e.g. in research).
\end{abstract}

\title{
Trust
}

Question: Please indicate how much you trust that the following institutions use information about you in an appropriate manner and with consideration for your personal privacy. I trust:

Scale: 1 very much, 2 quite much, 3 not much nor little, 4 quite little, 5 very little, ( 6 no opinion) q12_2 The Social Insurance Institution of Finland (Kela)

q12_3 Registration and statistics authorities (e.g. National Institute for Health and Welfare, Statistics Finland)

q12_4 Universities

q12_15 Civic social and health care organizations such as Red Cross, Unicef, Child Welfare, Church Aid, etc.

q12_6 Public social and health care provider organizations

q12_7 Private social and health care provider organizations

\section{Control}

Question: With regard to your personal social and health information and its use, how important do you consider the following factors? Please indicate the importance of each statement from your point of view:

Scale: 1 very important, 2 quite important, 3 not very important, 4 not at all important, (5 no opinion).

q14_1 Public authorities supervise the appropriate use of your personal health information.

q14_2 You have an opportunity to see the information that concerns you.

q14_3 You have the opportunity to correct possible mistakes related to information about you.

q14_4 You can refuse the use of information that concerns you.

q14_5 You can see what purposes the information about you is used for and who the users are.

\section{Intention to share (A)}

Question: Would you allow the use and combination of your unidentifiable social and health information for the following purposes? Unidentifiable means that it is not possible to recognize your identity from the information and your name, social security number of other similar information is not transferred to the recipient.

Scale: 1 yes, my information can be used freely, 2 my information can be used upon my separate consent, 3 my information is not to be used, (4 no opinion)

q17_1 For the development of treatments and more effective cures for diseases

q17_2 For the development of new (precision) medicines

q17_3 For the development of new social and medical instruments and services

q17_4 For the identification of possible health risks in my residential area

q17_5 For the identification of possible health risks related to me personally

q17_6 For the development of effectiveness and quality of social and health services

q17_7 For other medical research purposes 


Intention to share (B)
Question: Would you allow the use of your unidentifiable information for the development of
medicine when combined with your personal health and patient information? Unidentifiable
means that it is not possible to recognize your identity from the information and your name, social
security number of other similar information is not transferred to the recipient.
Scale: 1 yes, my information can be used freely, 2 my information can be used after my separate
consent, 3 my information is not to be used, (4 no opinion)
q21_1 Genetic information
q21_2 $\quad$ Physical activity information
q21_3 Alcohol consumption information
q21_4 Residential area information
q21_5 $\quad$ Grocery shopping information
q21_6 $\quad$ Travelling information


Table 1. Comparison of sample and target population

\begin{tabular}{|l|l|l|}
\hline & $\begin{array}{l}\text { Survey sample } \\
\text { (N 2338) }\end{array}$ & $\begin{array}{l}\text { Finnish } \\
\text { population }\end{array}$ \\
\hline Age group & $14.8 \%(345)$ & $19.4 \%$ \\
$-15-27$ & $15.2 \%(356)$ & $21.1 \%$ \\
$-28-40$ & $25.6 \%(599)$ & $20.5 \%$ \\
$-41-53$ & $25.6 \%(599)$ & $22.0 \%$ \\
$-54-66$ & $18.8 \%(439)$ & $17.1 \%$ \\
$-67-79$ & & \\
Gender & $56.2 \%(1315)$ & $50.1 \%$ \\
- Female & $43.8 \%(1023)$ & $49.9 \%$ \\
- Male & &
\end{tabular}


Table 2. Descriptive statistics of variables and factor loadings

\begin{tabular}{|c|c|c|c|c|c|c|c|}
\hline \multicolumn{3}{|c|}{ Variables* } & \multicolumn{5}{|l|}{ Factors* } \\
\hline Var. id. & Mean & Std. & F1 (Q17) & F2 (Q21) & F3 (Q12) & F4 (Q14) & F5 (Q24) \\
\hline q24_1 & 1.56 & 0.63 & & & & & 0.668 \\
\hline q24_2 & 1.63 & 0.65 & & & & & 0.768 \\
\hline q24_3 & 1.63 & 0.65 & & & & & 0.772 \\
\hline q24_4 & 1.76 & 0.67 & & & & & 0.682 \\
\hline$q 12 \_2$ & 2.10 & 0.92 & & & 0.754 & & \\
\hline$q 12 \_3$ & 2.17 & 0.95 & & & 0.793 & & \\
\hline$q 12 \_4$ & 2.34 & 0.89 & & & 0.682 & & \\
\hline$q 12 \_5$ & 2.67 & 1.01 & & & 0.666 & & \\
\hline$q 12 \_6$ & 2.11 & 0.90 & & & 0.774 & & \\
\hline$q 12 \_7$ & 2.23 & 0.93 & & & 0.600 & & \\
\hline q14_1 & 1.41 & 0.60 & & & & 0.598 & \\
\hline q14_2 & 1.28 & 0.55 & & & & 0.746 & \\
\hline q14_3 & 1.30 & 0.53 & & & & 0.767 & \\
\hline q14_4 & 1.42 & 0.65 & & & & 0.667 & \\
\hline q14_5 & 1.38 & 0.59 & & & & 0.776 & \\
\hline q17_1 & 1.59 & 0.58 & 0.809 & & & & \\
\hline q17_2 & 1.72 & 0.62 & 0.756 & & & & \\
\hline q17_3 & 1.72 & 0.59 & 0.747 & & & & \\
\hline q17_4 & 1.68 & 0.60 & 0.701 & & & & \\
\hline q17_5 & 1.65 & 0.58 & 0.621 & & & & \\
\hline q17_6 & 1.70 & 0.59 & 0.756 & & & & \\
\hline q17_8 & 1.75 & 0.59 & 0.726 & & & & \\
\hline q21_1 & 1.87 & 0.64 & & 0.537 & & & \\
\hline$q 21 \_2$ & 1.92 & 0.68 & & 0.754 & & & \\
\hline q21_3 & 1.85 & 0.69 & & 0.709 & & & \\
\hline$q 21 \_4$ & 1.85 & 0.66 & & 0.660 & & & \\
\hline$q 21 \_5$ & 1.97 & 0.73 & & 0.776 & & & \\
\hline q21_6 & 2.00 & 0.70 & & 0.790 & & & \\
\hline
\end{tabular}

*) Factor and variable id's are based on the variable labels used in the original survey data. 
Table 3. Test statistics of the empirical model

\begin{tabular}{|llllll|}
\hline M odel fit & \multicolumn{1}{l|}{ 1654.056, d.f. 343, P 0.000 } & & \\
Chi-square test of model fit & 0.041 & & & & \\
Root mean square error of approximation (RM SEA) & 0.045 & & & & \\
Standardized root mean square residual (SRM R) & 0.964 & & & & \\
Comparative fit index (CFI) & 0.961 & & & & \\
Tucker-Lewis index (TLI) & & & & & \\
& $\mathbf{Q 2 4}$ & $\mathbf{Q 1 2}$ & $\mathbf{Q 1 4}$ & $\mathbf{Q 1 7}$ & $\mathbf{Q 2 1}$ \\
Construct reliabilities & 0.729 & 0.769 & 0.721 & 0.820 & 0.787 \\
Average variance extracted (AVE) & 0.891 & 0.878 & 0.842 & 0.929 & 0.905 \\
Composite reliability (CR) & 0.889 & 0.881 & 0.835 & 0.932 & 0.905 \\
Cronbach's alpha & & & & \\
\hline
\end{tabular}




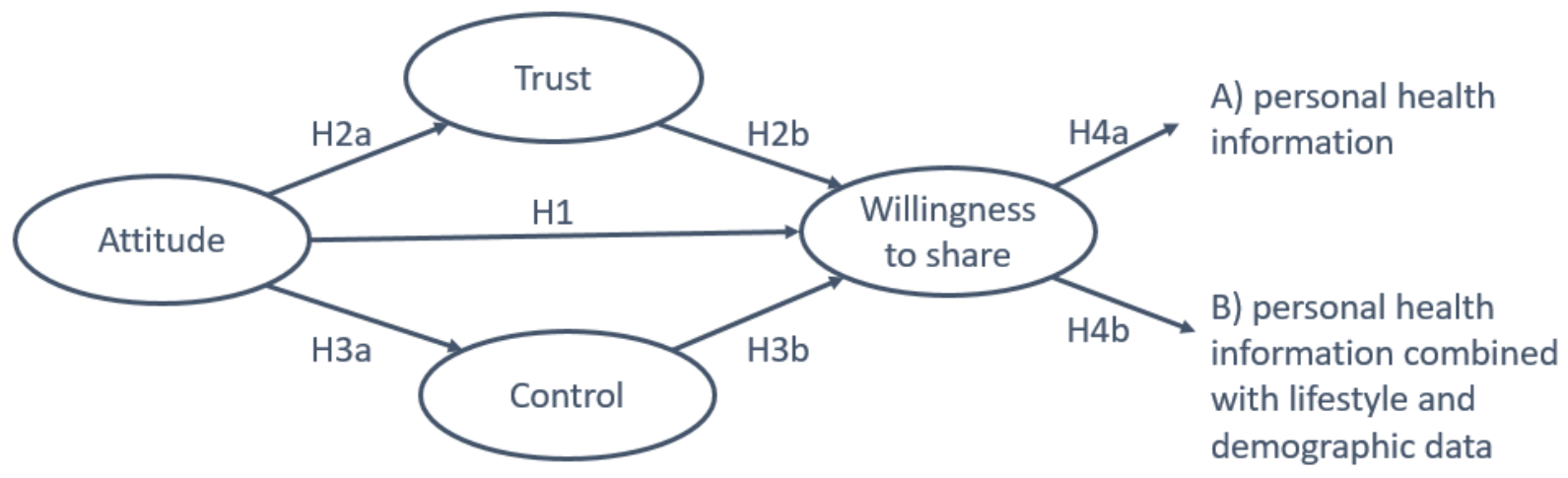

Figure 1. Antecedents to willingness for sharing personal health information 


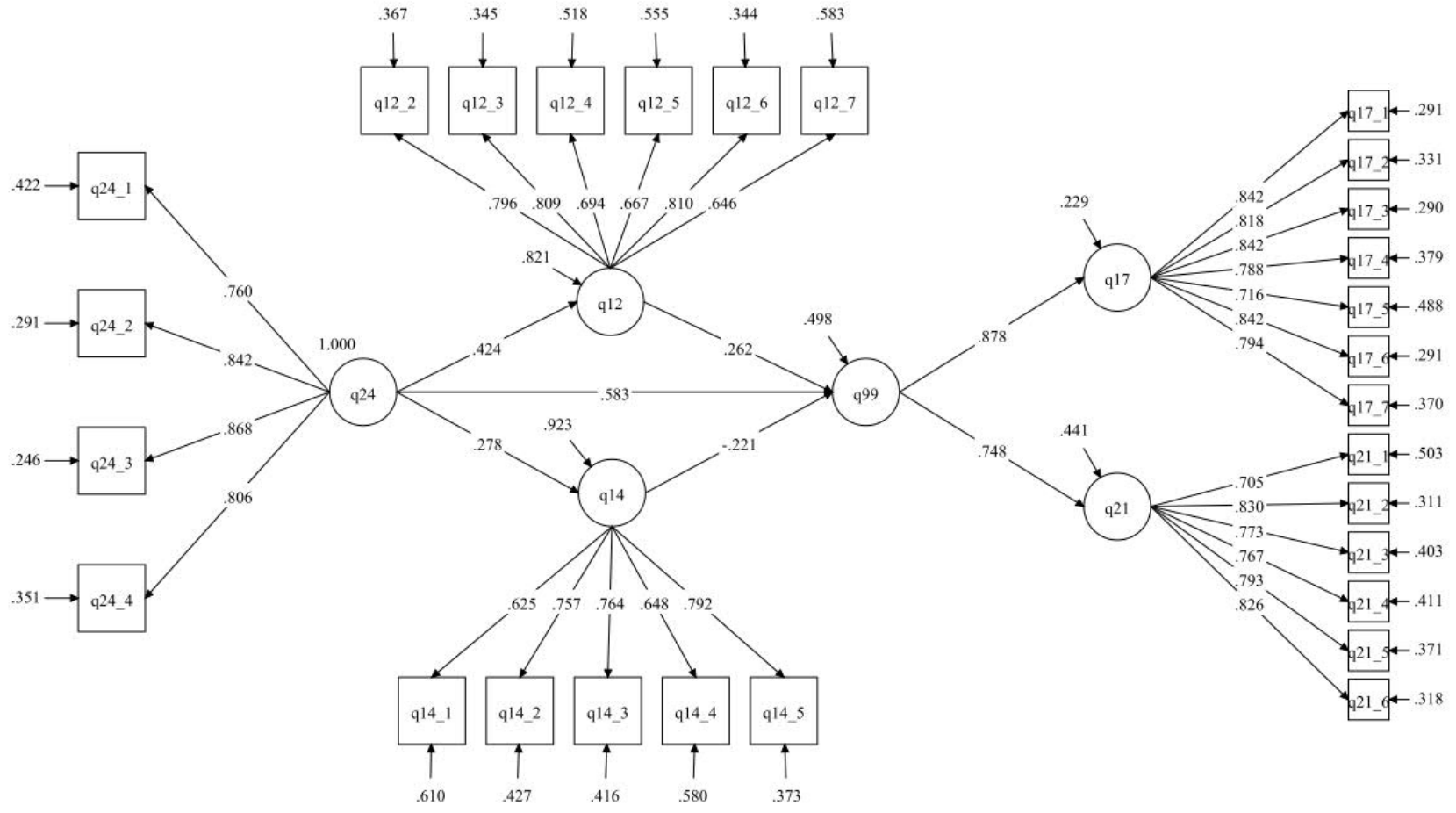

Figure 2. The empirical model 